\title{
Study on Management Efficiency and Countermeasures of Education Science and Technology Enterprises
}

\author{
Liu Yi \\ School of Economics, Northwest University of Political Science and Law, Xi `an, 710063, China
}

Keywords: education science and technology; listed enterprises; operating efficiency; super efficiency DEA-Tobit model

\begin{abstract}
Education science and technology has become a top priority in building a strong country. Therefore, it is necessary to study the operating conditions of education science and technology enterprises (EST). Based on the analysis of the financial statements of 63 education science and technology enterprises listed on A shares, taking the total business income and net profit as the output factors, taking the fixed assets value and the staff salaries as the input elements, we use the two-stage super efficiency DEA-Tobit model to make an empirical analysis. The results show that: the western region of the education science and technology enterprises operating efficiency should be higher than other areas, and pay taxes, debt scale and the proportion of property rights are the main factors influencing the education science and technology enterprises business efficiency of technological innovation, and the operation efficiency of EST: asset liability ratio and the proportion of property is higher than that of the inefficient management the enterprise, which means the former is better at play "leverage effect", therefore, it will help to improve the operational efficiency of the education science and technology enterprises by improving the scale of debt and increasing the policy support to the education science and technology enterprises.
\end{abstract}

\section{Introduction}

After the end of the cold war, with the reduction of military expenditure and the shrinking scale of military enterprises, countries began to reform the military industry, among which the development of military education technology model is an important direction of reform. While building a science and technology strong power, due to the strong spillover effect of high-end science technology, applying it to private enterprises will contribute to the better and faster development of national economic construction. Education advanced technology enterprise bear the infiltration and fusion the historical mission of science and technology, although there is a strong support of the country, but in essence is the enterprise market, its operating efficiency to a great extent, are at the mercy of market rules, especially the original national defense war industry enterprise mainly rely on the government's transfer payment to maintain its operation, in the process of "conversion" is bound to strongly impact by the market, therefore, further study of the present stage education technology enterprise management status, increase operational efficiency is particularly important. 


\section{Literature review}

In recent years, there are more and more literatures on the development mode of education science and technology enterprises, and different scholars have expounded their unique opinions from different perspectives. Mustafa Ozden (2007) founded that there is a big inadequacy in science and technology education in Turkey as compared to other countries. According to the result of this research, the main problems with science and technology education are insufficient number of science and technology teachers' taking active role in the preparation of the programs, the insufficient in-service training of the science teacher in the transition state of a new program, the huge numbers of the students in the class, the informational education orienting students towards only exam achievement; Suvi Tala's (2011) research shows that the unification of science and technology education from the viewpoint of recent studies, which have revealed an unexpectedly deep bi-directional relationship between the development of science and technology. Additionally, he thinks that technoscience supports in a natural way the teaching solutions, which put weight on personal conceptualization for learning.

In conclusion, many related studies of education science and technology enterprises, different methods, most of the literature only qualitative description the education science and technology in the enterprise market development problems and risks, part of the quantitative education science and technology enterprises financing efficiency literature sample too little, can't reflect the overall condition of the education science and technology integration sector and regional differences, and studies of education science and technology integration listed enterprise operation efficiency is at A blank, therefore, this article is based on the super-efficiency DEA-Tobit model, this paper conducts an empirical study on the operating efficiency of 63 education science and technology enterprises listed on A-share.

\section{Model construction and variable selection}

\subsection{Traditional DEA model}

In 1978, A data envelopment analysis method (DEA model) was first proposed by A Charnes, w. w. cooper and e. r. hodes to evaluate the relative effectiveness of the same departments. For all DMU (decision units of the same type), Technical Efficiency (TE) can be obtained by using the traditional BBC model, and then Pure Technical Efficiency (PTE) and Scale Efficiency (SE) can be further obtained. The linear planning is as follows:

$$
\text { s.t. }\left\{\begin{array}{c}
\min \left[\theta-\varepsilon\left(\widehat{e^{T}} S^{-}+e^{T} S^{+}\right)\right] \\
\sum_{j=1}^{n} X_{j} \lambda_{j}+S^{-}=\theta X_{0} \\
\sum_{j=1}^{n} X_{j} \lambda_{j}-S^{+}=Y_{0} \\
S^{-} \geq 0, S^{+} \geq 0, \lambda_{j} \geq 0, \sum_{j=1}^{n} \lambda_{j}=1, j=1,2, \ldots, n
\end{array}\right.
$$

Among them, $S^{-}\left({s_{1}}^{-},{s_{2}}^{-},{s_{3}}^{-}, \ldots s_{n}{ }^{-}\right), S^{+}\left({s_{1}}^{+},{s_{2}}^{+},{s_{3}}^{+}, \ldots s_{n}{ }^{+}\right)$are the relaxation variable, $\mathrm{X}$ and $\mathrm{Y}$ are the input factor and output factor respectively or the decision unit DEA is effective. If 0 or 0 , weak DEA is effective. If $<1$, the decision unit DEA is invalid.

\subsection{Super-efficient DEA model}

In 1993, Andersen and Petersen proposed that the traditional DEA model solved the defect of not being able to rank the efficiency values of multiple effective DMU at the same time, which enabled the effective decision units to be compared. The linear programming is as follows: 


$$
\begin{gathered}
\min \left[\theta-\varepsilon\left(\widehat{e^{T}} S^{-}+e^{T} S^{+}\right)\right] \\
\text {s.t. }\left\{\begin{array}{c}
\sum_{j=1, j \neq 0}^{n} X_{j} \lambda_{j}+S^{-}=\theta X_{0} \\
\sum_{j=1, j \neq 0}^{n} X_{j} \lambda_{j}-S^{+}=Y_{0} \\
S^{-} \geq 0, S^{+} \geq 0, \lambda_{j} \geq 0, \sum_{j=1}^{n} \lambda_{j}=1, j=1,2, \ldots, n
\end{array}\right.
\end{gathered}
$$

The difference between formula statement and formula statement is: formula statement removes the evaluated decision unit from the reference system, so that when evaluating a decision unit, the selected reference system does not contain the evaluated decision unit. For the input-oriented super-efficiency DEA model, the super-efficiency DEA can be used to measure the ratio of the input being amplified, but such magnification does not harm the effective frontier state formed by other decision units. For the effective decision-making unit of DEA, when its input amount increases to a certain proportion and is smaller than its super efficiency value, its effective state will not change. However, the value of the inefficient decision unit is consistent with the CCR-DEA model.

\subsection{Tobit model}

The Tobit model, also known as the truncated regression model or the deleted regression model, is a kind of limited dependent variable regression. It refers to a type that the dependent variable, although it is roughly continuous in positive value, contains a part of the observed value with the value of 0 in the correction rate. The classic Tobit model is a generalization of the Probit regression model by James Tobin. The regression model is as follows:

$$
\begin{array}{r}
y^{*}=\beta^{\prime} x_{i}+u_{i}, \\
y_{i}^{*}=y_{i} \quad \text { if } y_{i}^{*}>0 \\
y_{i}^{*}=0 \quad \text { if } y_{i}^{*} \leq 0 \\
u_{i} \sim N\left(0, \sigma^{2}\right)
\end{array}
$$

Where, $y_{i}^{*}$ is the potential dependent variable and is observed when the latent variable is greater than 0 , and is $y_{i}$; Transversal at 0 for less than or equal to $0, x_{i}$ is the independent vector, $\beta$ is the coefficient vector, $u_{i}$ is the error term, obeys the normal distribution. If the model with truncated data is estimated by ordinary least square method, the coefficient estimation should be done by the maximum likelihood estimation method.

\subsection{Index selection}

Education science and technology enterprises general for large-scale education technology enterprise, with fixed assets value is bigger, the characteristics of the worker Numbers, in view of this, this article selected according to the cost-benefit principle two input indicators and output indicators, input indicators (unit: one hundred million yuan) to fixed assets value and pay workers compensation (unit: one hundred million yuan); The output index is gross revenue (unit: 100 million yuan) and net profit (unit: 100 million yuan).

\subsection{Sample selection}

As most of the previous literature only selected 10-30 listed companies as the sample data, it could not reflect the overall situation of education technology enterprise and could not represent the development status of education technology listed companies in different regions. Therefore, in this paper, 63 enterprises listed in the technology sector of education in a-share (with the exception of 
those listed for less than three years, whose net profit is negative and whose stock is suspended) were used as sample sources for empirical analysis, and in 2016, the data were all from the financial reports published by the financial network of tonghuashun, wind financial database and each enterprise.

\section{The empirical analysis}

In this paper, 63 EST fusion enterprises were analyzed by traditional DEA, and mydea 1.05 software was used for super-efficiency ranking. Finally, factors affecting operational efficiency of civil-military fusion enterprises were returned with Tobit model. Due to layout limitations, this paper only lists Tobit regression results.

\subsection{Tobit variable selection}

In view of the heavy industry nature of EST in general, large investment in fixed assets and easy to form market concentration, the following 6 representative indicators were selected as regression explanatory variables with 2016 as the research period:

Asset scale ratio: The ratio of total assets of all listed companies to total assets of all listed companies is used to represent the proportion of assets in the industry. Asset is used in this paper.

Market concentration: It refers to the total revenue of all listed companies compared with the total revenue of all listed companies, which indicates the market concentration degree of enterprises in the industry. Market is used in this paper.

Non-operating expense ratio: The agency cost is approximately quantified through the ratio of non-operating expenditure to total revenue, reflecting the moral risk caused by principal-agent relationship and the impact of adverse selection on the operating efficiency of listed companies. Non-operating is used in this paper.

Rate of payment: In this paper, SF is used to measure the impact of tax paid by enterprises on enterprise operating efficiency. Payment is used in this paper.

Debt service ratio: The cash ratio of the debt paid by listed companies to total revenue is used to measure the influence of "financial leverage effect" on the operating efficiency of enterprises, which is expressed by Debt.

Property right proportion: Is the ratio of liabilities to owners' equity of each listed enterprise to measure the influence degree of equity concentration on the operating efficiency of the listed enterprise. Property is used in this paper.

Then the Tobit regression equation constructed in this paper is:

$$
Y=\alpha+\beta_{1} \text { Asset }+\beta_{2} \text { Market }+\beta_{3} \text { Non-operating }+\beta_{4} \text { Payment }+\beta_{5} \text { Debt }+\beta_{6} \text { Property }+\varepsilon
$$

Where $\alpha$ is the intercept term, $\beta_{i}$ is each explanatory variable coefficient, $Y$ is the explained variable and $\varepsilon$ is residual.

\subsection{Regression results}

The Tobit model was regressed by stata 13.0, and the results are shown in the following table 1 . 
Table 1

\begin{tabular}{ccccc}
\hline variable & Coef & Std & $\mathrm{t}$ & $\mathrm{P}$ \\
\hline Asset & -0.097 & 1.760 & -0.06 & 0.956 \\
\hline Market & 0.910 & 2.426 & 0.38 & 0.709 \\
\hline Non-operating & 5.136 & 6.037 & 0.85 & 0.399 \\
\hline Payment & 1.194 & 0.745 & 1.69 & 0.097 \\
\hline Debt & -0.072 & 0.063 & -1.79 & 0.079 \\
\hline Property & 0.119 & 0.055 & 2.14 & 0.037 \\
\hline
\end{tabular}

It can be seen that only three explanatory variables: Payment、Debt and Property passed the 10\% significance test. The following conclusions can be drawn:

(1) Production scale, market concentration and non-business expenses rate for EST efficiency of listed companies management basic has nothing to do, this suggests that asset size, how much revenue accounted for in the industry is not for EST of listed companies operating efficiency have a significant impact, and principal-agent relationship caused by the additional agency cost also can't have a significant impact to the enterprise the management efficiency, this suggests that the present EST listed companies on corporate governance in a relative advantage position.

(2) Pay tax on the scale of EST of listed companies operating efficiency have a significant positive influence, in this to say, the bigger pay taxes while cause net income decreases, but the area for military and EST such high-tech enterprises have some favorable policies such as tax return, China's heavy industry in Beijing as an example, pay various taxes in 2016 a total of 1.207 billion yuan, but the return of taxes and fees as high as 1.68 billion yuan. Local governments will redistribute the tax paid by the high-tech enterprises to the enterprises, so that the enterprises have more capital to improve the operation efficiency. By statistical computing, super efficiency value in the effective frontier the eight EST of listed companies pay taxes than 0.12, while the rest are super efficiency invalid enterprises pay taxes than 0.07, indicating that the higher pay taxes than the negative impact of enterprise operation efficiency can be refund plenty of preferential policies to eliminate by the positive impact of enterprise management efficiency.

(3) Debt scale of the enterprise the management efficiency is a weak negative significant impact, but at the same time the proportion of property rights strong positive significant influence on the enterprise the management efficiency, this shows that although the liabilities will cause the enterprise net profit decrease, in turn, the more negative impact on business efficiency, but the height of the equity focus on improve the management efficiency of enterprises will be a strong positive impact. By statistical computing, super efficiency value in the effective frontier the eight EST of listed companies to repay the debt ratio 0.49 , property ratio is 2.48 , and the rest in the super efficiency invalid corporate debt ratio 0.39 , property ratio is 0.76 , which suggests that the appropriate to raise the debt scale of the negative impact of enterprise management efficiency can be equity concentrated enough to enterprise and the positive impact of operational efficiency.

\section{Conclusions and Suggestions}

In this paper, 63 listed companies with civil-military integration were ranked by super-efficiency DEA model, and several factors affecting civil-military integration were analyzed by combining with Tobit model. The following conclusions were drawn: Assets ratio, market concentration and non-business expenses rate for EST efficiency of listed companies management basic has nothing to do, and pay the taxes and fees than ratio, ratio of debt scale and property has significant effects on the enterprise the management efficiency, this suggests that appropriate increase for EST assets and liabilities ratio has a positive influence on the management efficiency, and each region for EST support policy also helps to improve the management efficiency of enterprises. Based on the above conclusions, this paper gives the following countermeasures and Suggestions: 
(1) We will improve the productivity of EST, optimize asset allocation and improve scale efficiency. This requires enterprises to do to make themselves into the market, strengthen talent attraction and research investment, strengthen the awareness of competition and active construction of regional innovation technology alliance, promoting free flow of advanced factors of production, to speed up the pace of EST development, make the advanced military science and technology into EST more efficiently.

(2) The government should strengthen the support and motivation of civil-military integration enterprise policy, to broaden the scope of EST confirmation, reduce the corporate tax expenditure, for it owns advanced technology but inefficient enterprises to intensify policy tilt, appropriate more conducive to subsidies, guide EST to improve management efficiency.

(3) We should optimize the asset structure of EST and appropriately increase their financial leverage. However, we should pay attention to the control of financing costs, prevent companies from going bankrupt due to excessive indebtedness, maintain the relative concentration of corporate equity, and prevent external adverse factors from negatively impacting on business efficiency.

(4) To accelerate the process of EST asset securitization and scale, at present, China's EST asset securitization and probably only $40 \%$ or so, many high-quality military resources still belongs to a private company, its market value is not enough to show, therefore, the development of "education and financial" model, makes the EST financing channels in the biochemical, truly self-raised funds, self-financing and independent operation, will be the main direction of future EST.

(5) To speed up the marketization of EST restructuring process, but for some highly involved in national security strategy of the enterprise, according to their level of security decision government equity participation, in addition to try to optimize the structure of property rights as the guidance, encourage EST to realize high quality assets reorganization and integration, create, cross-platform international education science and technology enterprises across the group.

\section{References}

[1] Patterson M. C., Wadsworth C. Updating New Zealand's energy intensity trends: What has happened since 1984 and why? [M].Wellington: Energy Efficiency and Conservation Authority, 1993.

[2] Anderson, Petersen. N. C. A procedure for ranking efficient units in data envelopment analysis [J]. Management Science, 1993.

[3] Mustafa Ozden. Problems with Science and Technology Education in Turkey[J].Eursia Journal of Mathematics, Science \& Technology Education,2007,(3):157-166.

[4] Suvi Tala. Unified View of Science and Technology for Education: Technoscience and Technoscience Education [J]. Science \& Education, 2009, (18):275-298.

[5] Dilek Karahoca, Adem Karahoca, Hüseyin Uzunboylub. Robotics teaching in primary school education by project based learning for supporting science and technology courses [J]. Procedia Computer Science, 2011, (3):1425-1431. 